\title{
月五年五十二治明
}

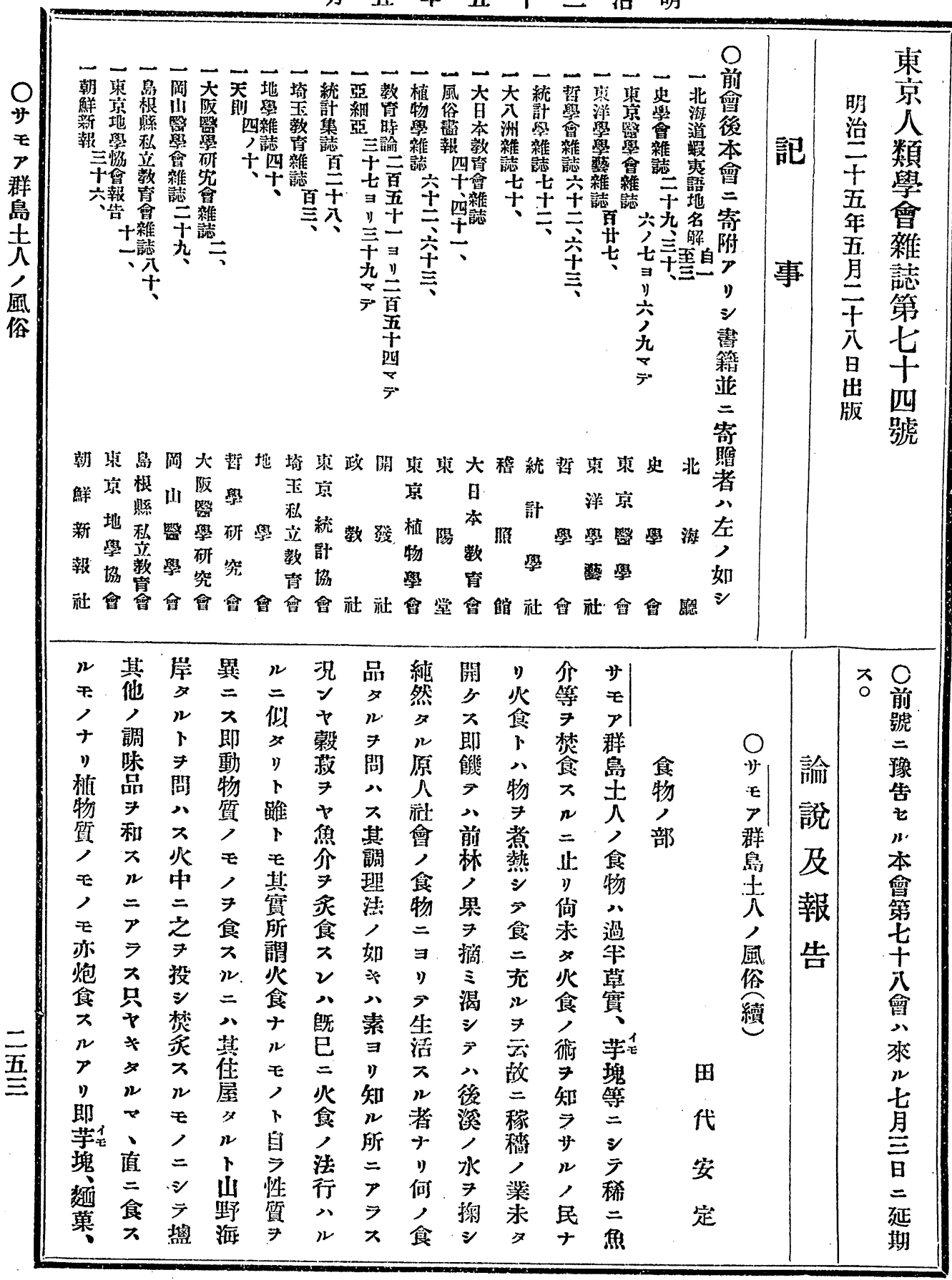


號四十七第誌雜會學類八京東

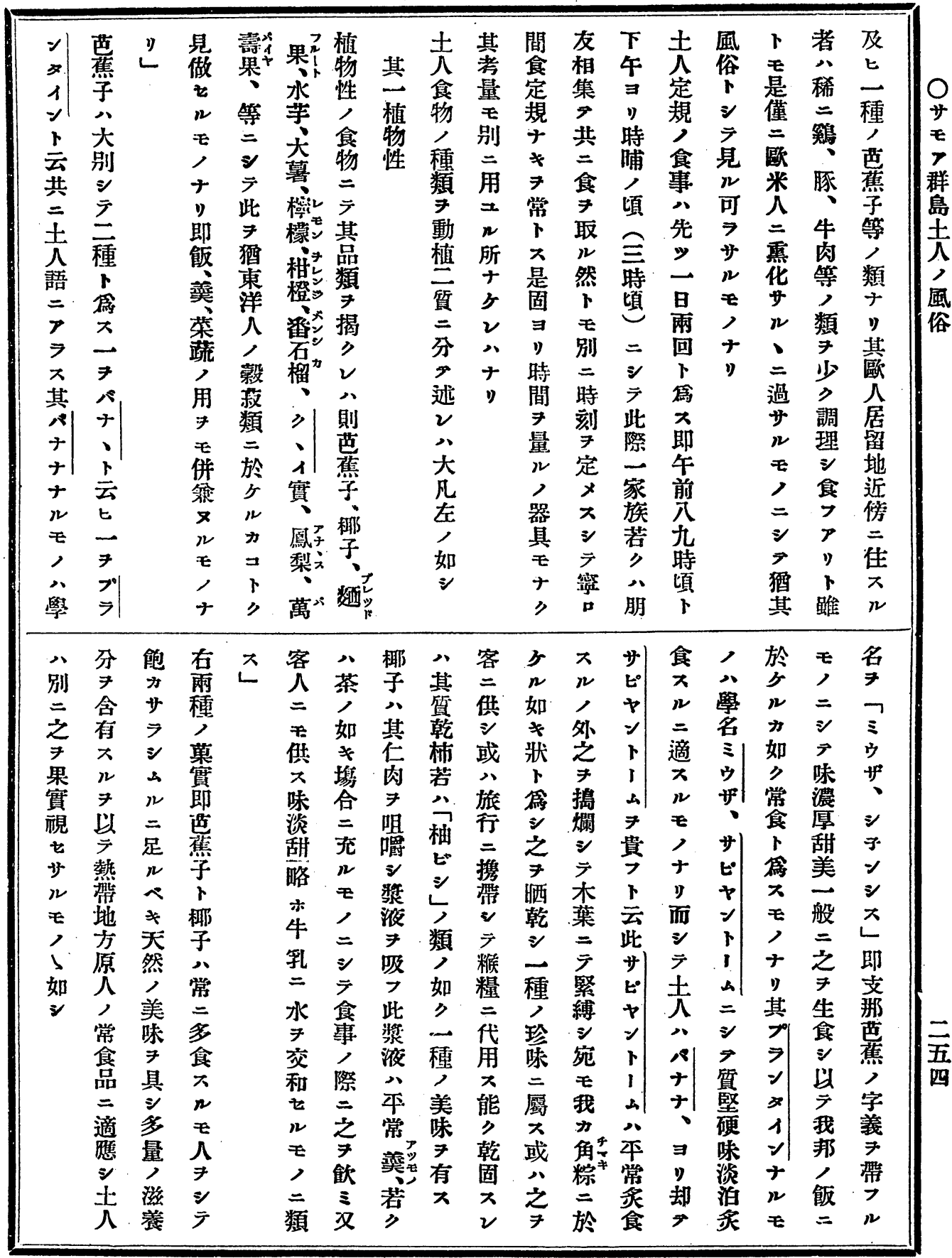




\section{月五年五十二治 明}

0

アシナノ大

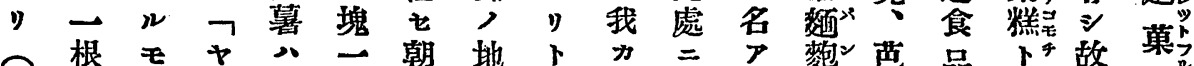

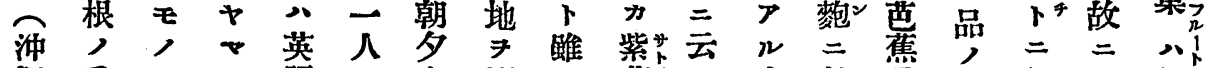

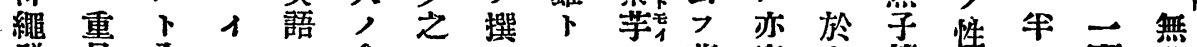

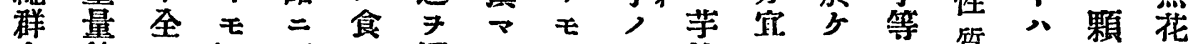
島往》し所二垠 $ス$ サ一塊ナルノ質七數果

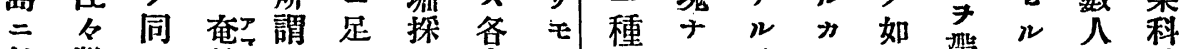

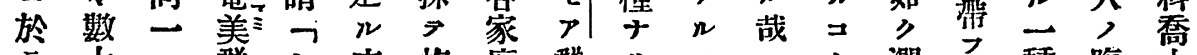

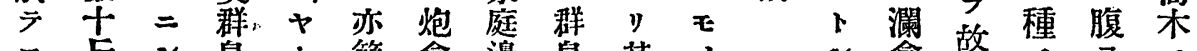
モ斤 年島, 簡食邀島其,

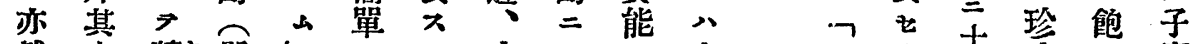

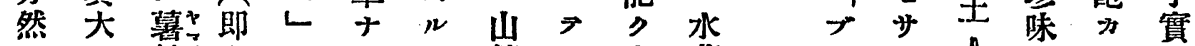

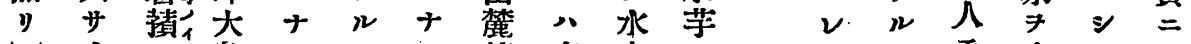

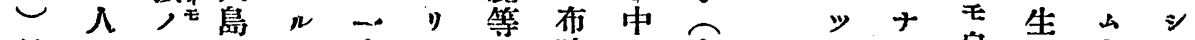
品, 一郡を食其三哇二方自少之方 類腕種点大植群生言、其 多、絕ノニトナテ島殖》

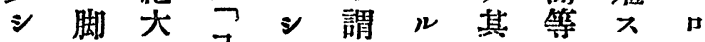

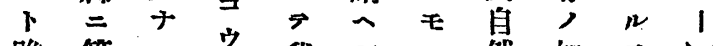
踓 等 以兄我 シ, 然如 7

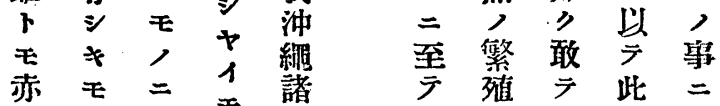
$>$ 之之一炮交

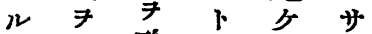
1爅琴菓 $心$ 兒 卜炮賞味其童

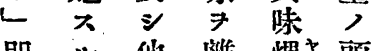
即ル他離 煨辛頭 麵ノノ 果将莎人口二

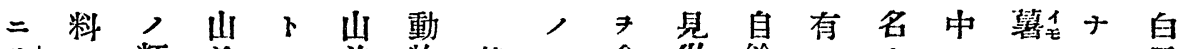

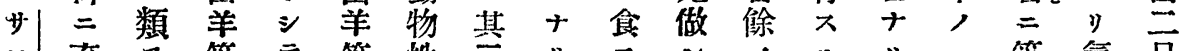

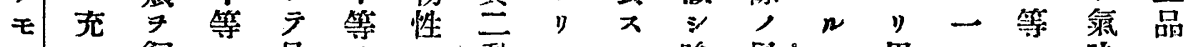

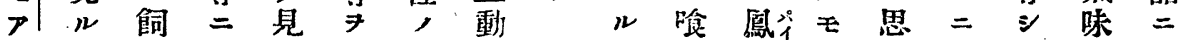

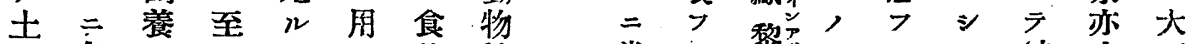

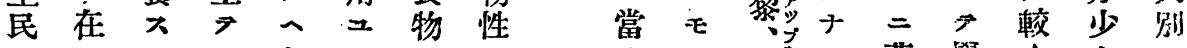
八》ル

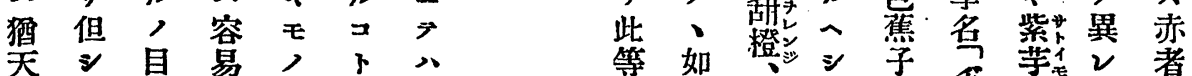

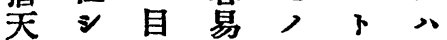
然 徃 的 $==>$ 魚

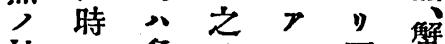
稙,多寻 ラ 而蟹

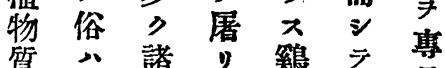
質 其葴 食 卵魚 物如, >其卜 三 五 值 航 事能名稀

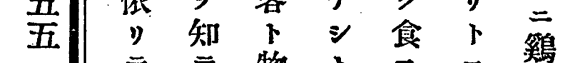
示 今 物

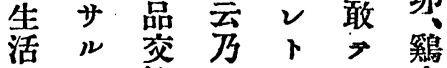
ス十換千基肉 只故元 等 豚 常食

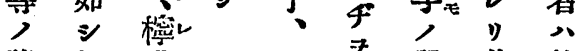
諸 便 檬虍 7 質 共 特 果 千等”相 7 二 $\exists$ 煨 等 間? 芋類等 $27 \%$ 二塊 $八$ 同?、然.朝 阻 等 唒牀、r 少

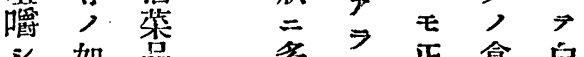
如嵒多 7 正食白 量矢方三者 喉 乾 二分年》充心

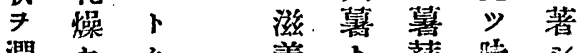

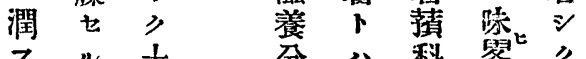

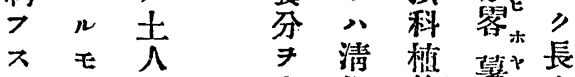

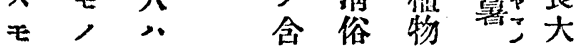




\begin{tabular}{|c|c|c|c|c|c|c|c|c|c|c|c|c|c|c|c|c|c|}
\hline 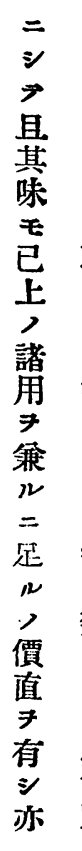 & 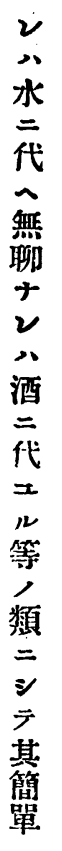 & 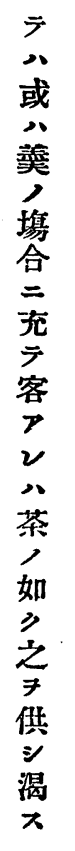 & 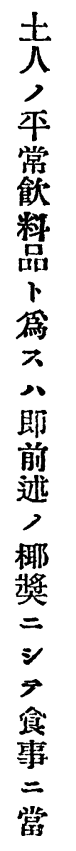 & $\begin{array}{l}\text { 歡 } \\
\text { 慗 }\end{array}$ & $\begin{array}{l}ナ \\
\text { У } \\
\text { - }\end{array}$ & 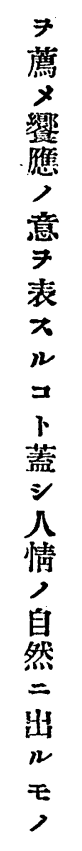 & 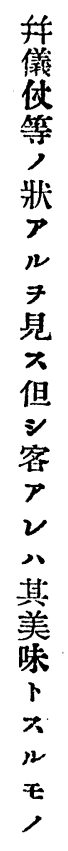 & 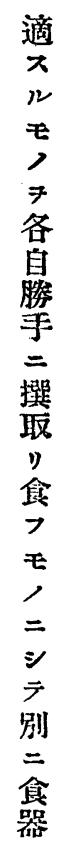 & 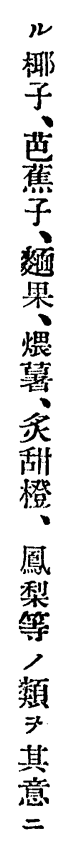 & 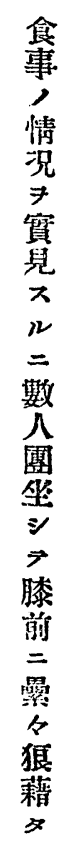 & $\begin{array}{l}\text { 㑒 } \\
\text { 筆 } \\
\text { 情 }\end{array}$ & i) & 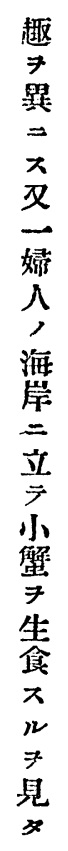 & 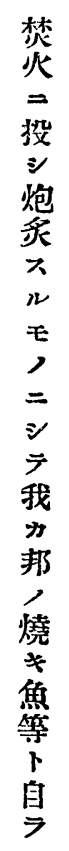 & 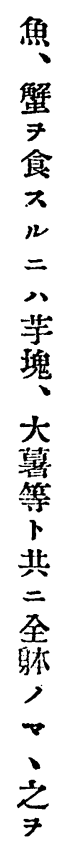 & 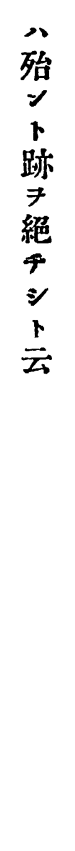 & 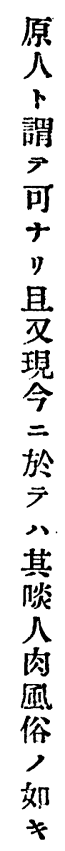 \\
\hline 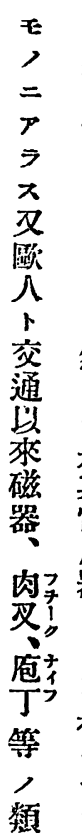 & 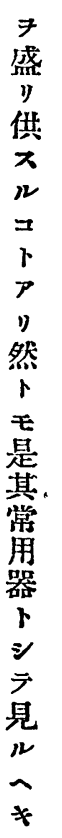 & 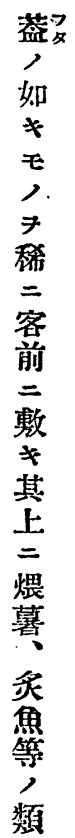 & 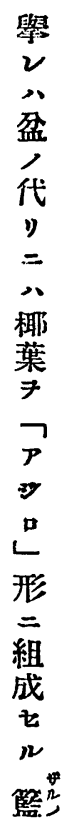 & 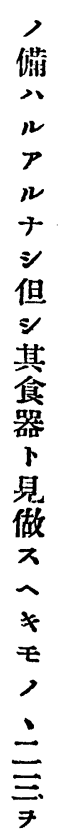 & 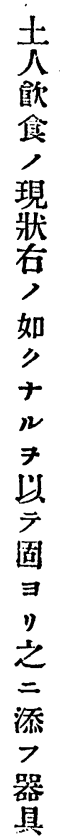 & $\begin{array}{l}\text { 湴 } \\
\text { 其 } \\
\text { 類 }\end{array}$ & $\stackrel{n}{\llcorner}$ & 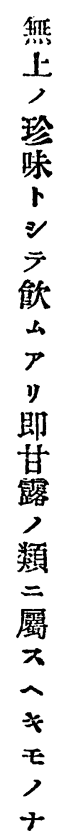 & 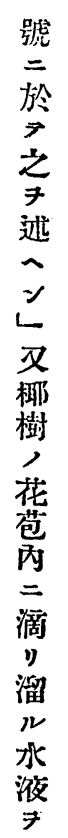 & 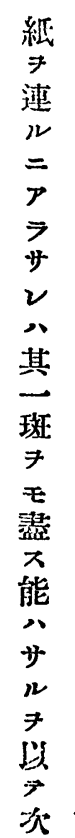 & 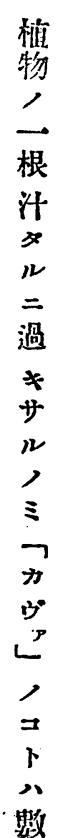 & 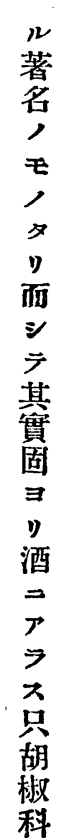 & 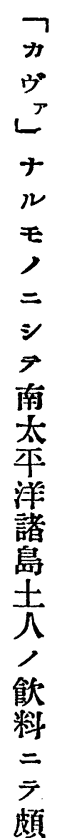 & 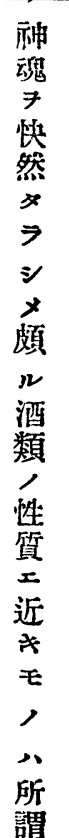 & 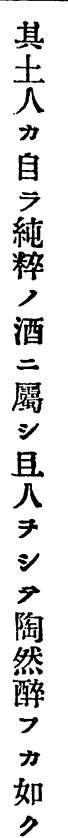 & 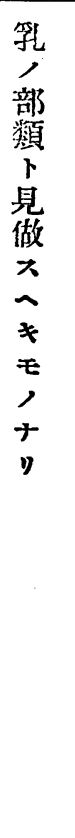 & 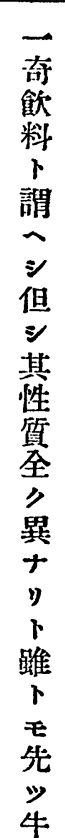 \\
\hline
\end{tabular}




\section{月五年五十二治明}

요

モ

$\boldsymbol{P}$

群

島

土

人

風

俗

會 7 如 ミ 外等 物 又心椰壱,

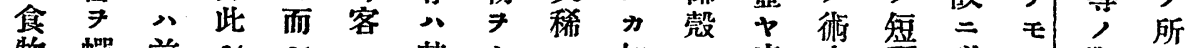

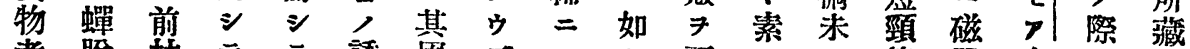

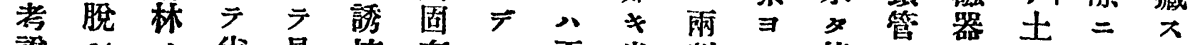

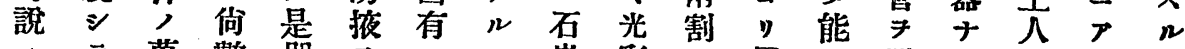
テ菓数 即 $尹>>$ 宸彩七用》附

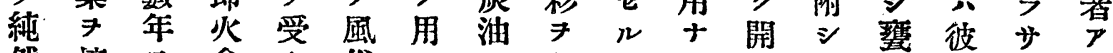

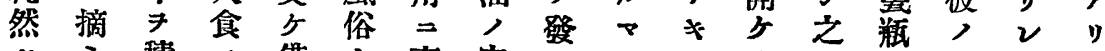

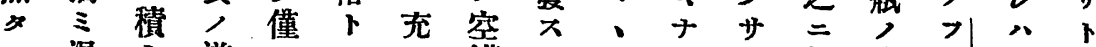

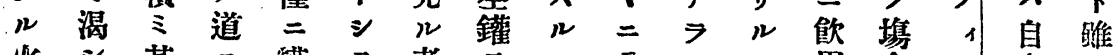
火

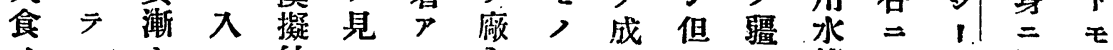

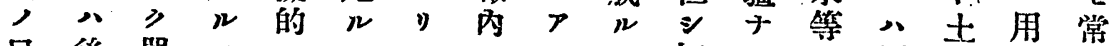

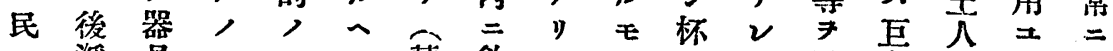

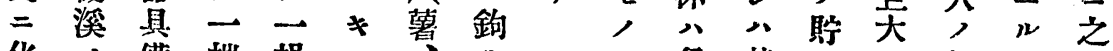

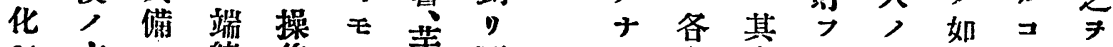

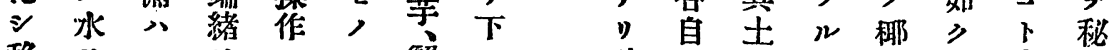

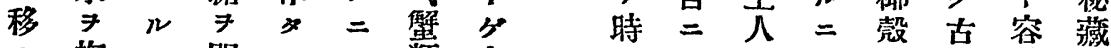

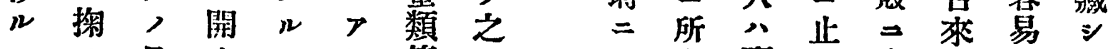
人ス日》

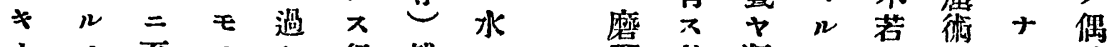

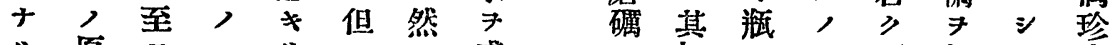

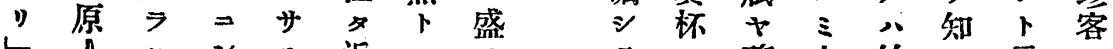

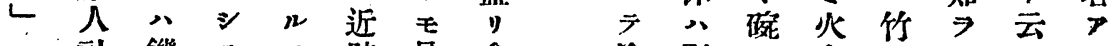
社饑 $>$ 特是食叙則 $ヤ$ 食二

此 $=$ 元含八刀ル其日其變生 $、$ 子ミテ前

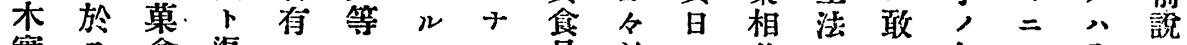

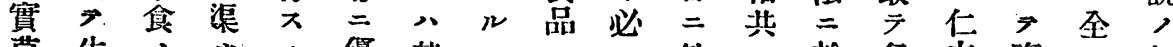

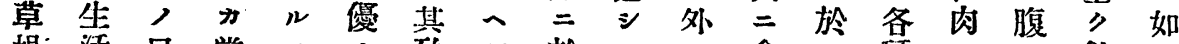

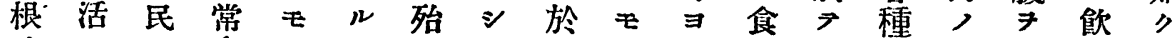

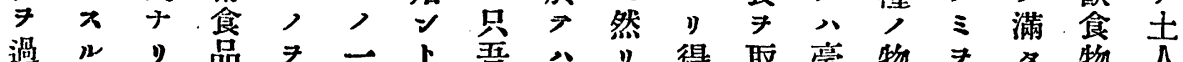
過

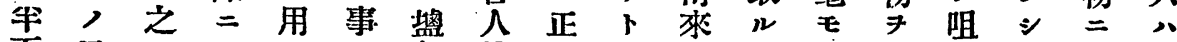

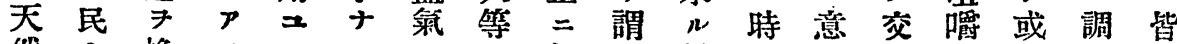

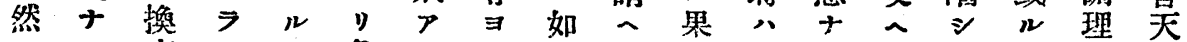

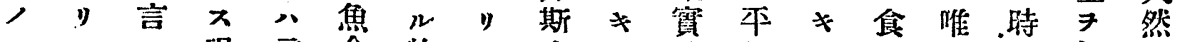
$\checkmark \quad \pi$ 况言介物

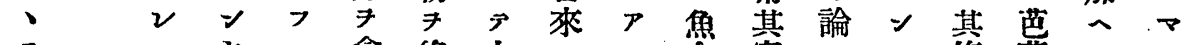
二小ヤ食終之方

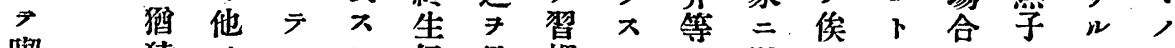

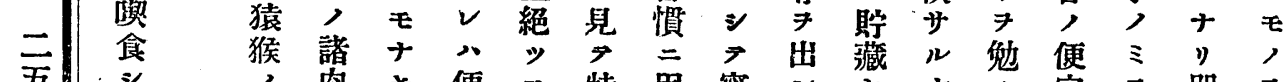

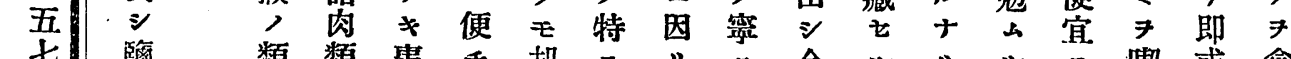

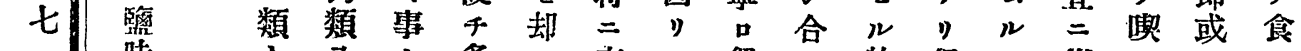

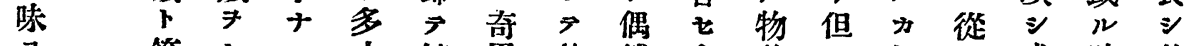

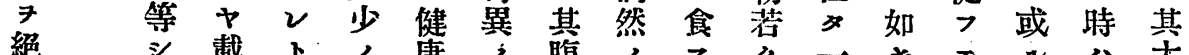

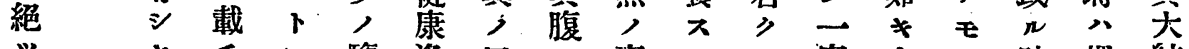

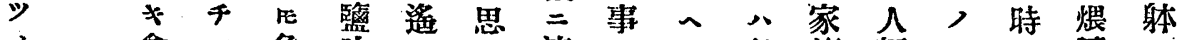

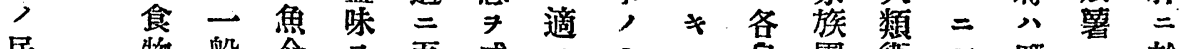
民物般柋 $尹$ 吾感 
號四十七第詰雜會學類入京東

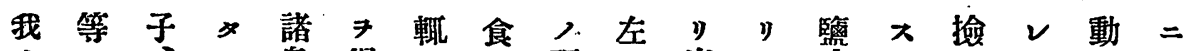

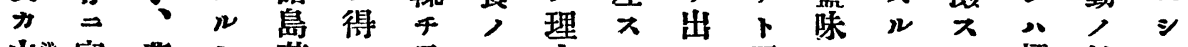
山学富蓿若

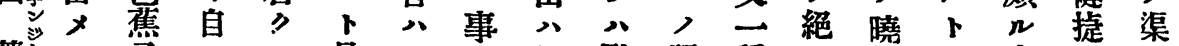

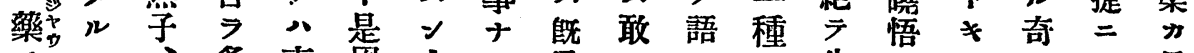

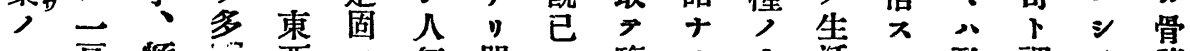

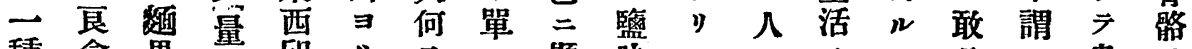

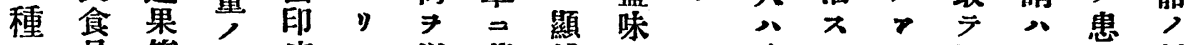

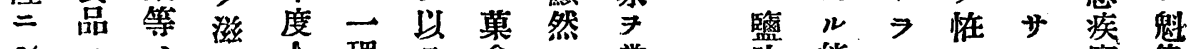

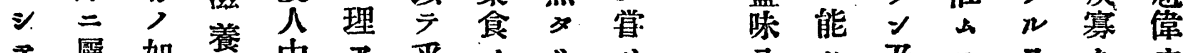

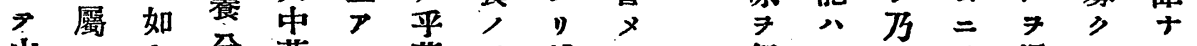

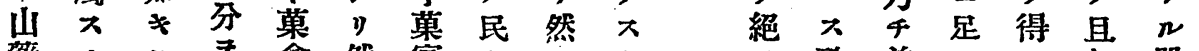

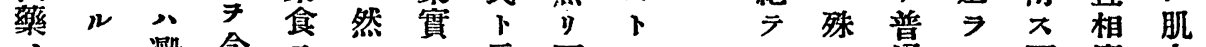
滋 澱 含

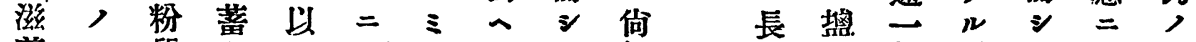

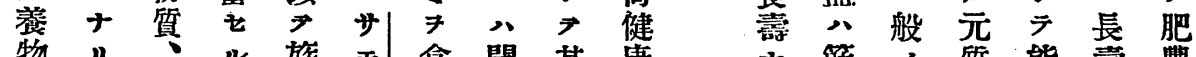

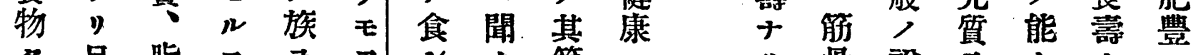

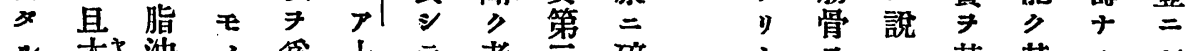

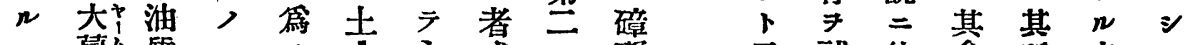

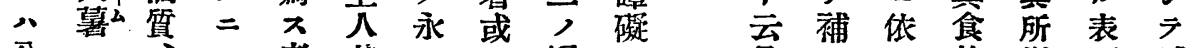

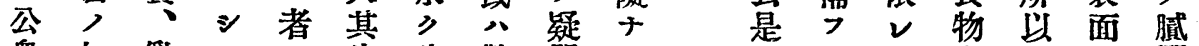
衆 如乳 $>$ 分他生警問 $*$ 亦,

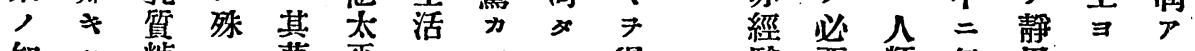

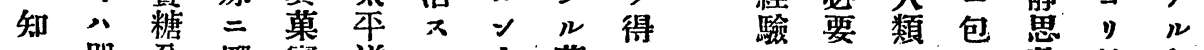

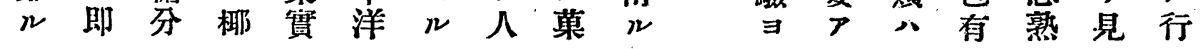

\section{$=₹ \equiv の \bigcirc$}

用着学ば雷

七刀 $ノ$ 壹

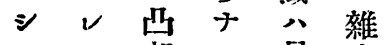

モ 起 $ト$ 貝菜

人雨女称榢嘍

+ 䫒 $n \pi$ 時 件

）節品代

У㷰学石,

二口ル器 モ

八人 ₹八,

宜如, 雨方

シ $\geqslant ナ$ 端 0

》ナり稍

兩止曲世

謴 0 其 ガ =

焦果ノり ら

口》節 細 $\backsim$ 三

页 シ 節

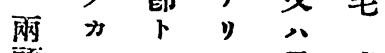

頭》間中雷米

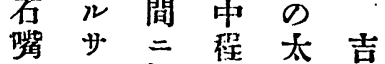

P 柄二鼓
六自健ノ刑得と至师所 千 度其 $卜$ 捡 $>$ ヤ , 發其 $九$ 先 $九$ 内 7 物加 間青容以入般

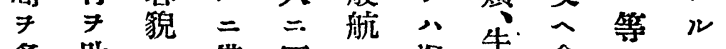
多助了㒖皆鿄等食了二

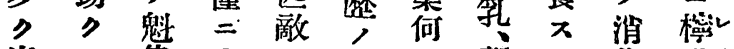

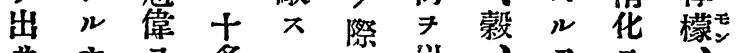
サナ $テ$ 名

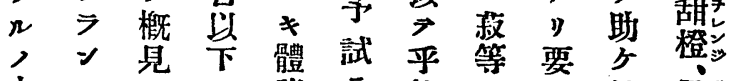

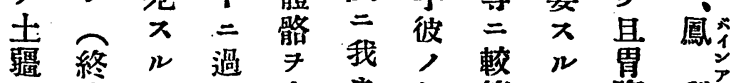

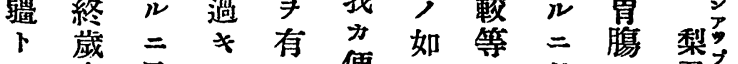

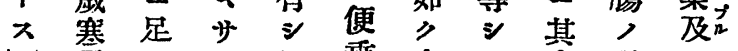
暑ルり且乘身 $*$ 人滋七 針亦 $三$ 肌船躱價身潤 五

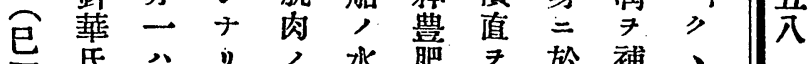
下氐

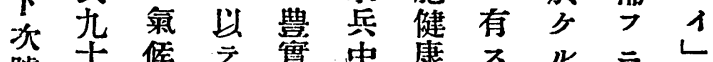
號十侯 度實中康 度人士七二ナッ效必實 方照八ル就ルナ角需へ

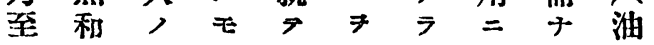

